\title{
Renal Involvement in COVID-19: A Review of the Literature
}

This article was published in the following Dove Press journal:

Infection and Drug Resistance

\section{Marco Giuseppe Migliaccio',* \\ Marco Di Mauro',* \\ Riccardo Ricciolino' \\ Giorgio Spiniello' \\ Vincenzo Carfora' \\ Nicoletta Verde' \\ Filiberto Fausto Mottola' \\ Nicola Coppola $\mathbb{( D}^{2}$ \\ On behalf of the Vanvitelli COVID-19 Group}

\footnotetext{
'Department of Translational Medical Sciences, University of Campania "Luigi Vanvitelli”, Naples, Italy; ${ }^{2}$ Department of Mental Health and Public Medicine, Infectious Diseases Unit, University of Campania “Luigi Vanvitelli”, Naples, Italy

*These authors contributed equally to this work
}

\begin{abstract}
Kidney injury may be a severe complication of acute respiratory syndrome coronavirus 2 (SARS-CoV-2) and contributes to worsen the prognosis. Various pathophysiological mechanisms can contribute to organ damage and impair renal function, proving the complexity of the virus activity and the resulting immunity response. We summarized the evidence of the literature on the prevalence of kidney involvement, on the pathogenic pathways and on its management.
\end{abstract}

Keywords: kidney injury, acute kidney injury, COVID-19, SARS-CoV-2

\section{Introduction}

In December 2019 a novel coronavirus (SARS-CoV-2) developed in Wuhan, China, and is expanding as a global outbreak causing Corona virus disease (COVID-19), with over 23 million cases across 188 countries and more than eight hundred thousand deaths[from "COVID-19 Dashboard by the Center for Systems Science and Engineering (CSSE) at Johns Hopkins University (JHU)". ${ }^{1}$ SARS-CoV-2 is a positive-sense single-stranded RNA virus that is spread via nose and mouth secretions including small droplets produced by coughing. The standard method of diagnosis is real-time reverse transcription polymerase chain reaction (rRT-PCR) on respiratory samples obtained by a nasopharyngeal swab. ${ }^{2}$ Heterogeneous clinical manifestations, from mild symptoms of upper respiratory tract illness to severe acute respiratory distress syndrome (ARDS) due to interstitial bilateral pneumonia, multiple organ failure, and death can occur. ${ }^{3,4}$

The ability of the virus to bind the ubiquitous angiotensin-converting enzyme (ACE)-2 receptors allows SARS-CoV-2 to target organs other than the lungs, such as the heart, central nervous system, gastrointestinal tract, etc. ${ }^{5,6}$ At present, the kidney is one of the several targets of COVID-19, but, as initially misdiagnosed, its involvement was considered negligible. However, acute kidney injury (AKI) in patients with COVID-19 is considered a marker of disease severity and a negative prognostic factor for survival. ${ }^{3,7}$

However, acute kidney injury (AKI), expressed as high amount of protein excretion and macroscopic hematuria, in patients with COVID-19 is considered a marker of disease severity and a negative prognostic factor for survival. ${ }^{3,7}$ In fact, a meta-analysis by Ali et $\mathrm{al}^{8}$ evaluating the outcome of COVID-19 subjects who developed AKI observed that those with severe AKI, defined as Kidney Disease Improving Global Outcome (KDIGO) stage III or need of acute renal replacement therapy (RRT), showed a higher mortality than those with stage I or II stage.
Correspondence: Nicola Coppola Department of Mental Health and Public Medicine, Infectious Diseases Unit, University of Campania "Luigi Vanvitelli", Via: L. Armanni 5, Naples, 80I3I, Italy

Tel +390815666719

Fax +39 08I 56660I3

Email nicola.coppola@unicampania.it 
This review will examine renal involvement, both direct and indirect, during SARS CoV-2 infection, in order to manage kidney complications in clinical practice.

\section{Methods}

A comprehensive computerized literature research was made to identify studies analyzing the renal implication of COVID-19 patients using MEDLINE, Google Scholar and EMBASE from December 2020 to August, 31 2020, involving both medical subject heading (MeSH) terminology and relevant keywords for search strings to locate articles. The following items were used: "renal complications", "kidney complication", "kidney", "acute kidney injury (AKI)", "COVID-19" and "SARS-CoV -2 ". The references of studies or reports were checked to find relevant information.

\section{Prevalence of Kidney Involvement During SARS-CoV-2 Infection}

Several studies evaluated the prevalence of kidney involvement in COVID-19 patients. These studies are summarized in Table 1.

A retrospective cohort study of 191 patients hospitalized for COVID-19 in Wuhan before Jan 31, 2020, showed that AKI occurred in $28(15 \%)$ patients and was more frequent in critically ill patients. A retrospective Chinese, single-center study, investigating renal injury in 333 patients hospitalized for COVID-19 pneumonia, observed a high percentage $(75.4 \%)$ of patients with acute kidney injury (mostly presented on admission with proteinuria or albumin to creatinine ratio) during hospitalization. Among these patients, only 35 (11\%) satisfied AKI criteria (KDIGO AKI criteria expanded: increase or decrease in serum creatinine by $50 \%$ during hospital stay $^{19,20}$ ) and a complete kidney function recovery was seen in $16(45.7 \%)$.

Overall, the incidence of AKI ranges from $0.5 \%$ to $80.3 \%$, although the study that reported the upper value ${ }^{8}$ considered only critically ill patients. ${ }^{21}$ In fact, the severity of pneumonia and ARDS have been identified as the most important risk factors for the development of kidney failure and subsequent poor function recovery. $^{22,23}$

However, we should underscore that the real incidence of AKI remains uncertain because of a lack of a clear definition and staging of this condition.

\section{Pathogenesis of Kidney Injury}

SARS-CoV-2 infects the host using the ACE-2, a membrane-bound peptidase, expressed more in the kidney than in other organs (lung, heart, intestine, and endothelial cells). ${ }^{24-26}$ While ACE converts angiotensin I (Ang I) to angiotensin II (Ang II), ACE2 degrades Ang II to angiotensin 1-7 [Ang-(1-7)]. Ang II plays a role in vasoconstriction and adrenergic stimulation, binding type 1 Ang II receptors (AT1), ${ }^{27}$ while Ang-(1-7) opposes the Ang II-AT1 axis through vasodilatation, and antiinflammatory and anti-fibrotic action, mainly increasing the production of nitric oxide.

By downregulating ACE2, SARS-CoV2 determines an increase in ACE activity and a shift to overproduction of Ang II. ${ }^{28}$ This leads to a proinflammatory (including complement activation) and pro-fibrotic state in the kidneys. The mechanisms of renal damage by SARS-CoV-2 are summarized in Figure 1. Renal damage may be due both to primary mechanisms, directly referred to the virus, and secondary mechanisms, linked to the hemodynamic and immune response to the virus.

\section{Direct Mechanisms of Renal Damage}

If in an advanced stage of disease, AKI can be ascribed to hypotension and low kidney perfusion due to hemodynamic, haemostatic or infectious factors, viral replication in the kidney parenchyma itself also plays a role. However, an acute proximal tubular injury is described in autopsies of subjects who died of COVID-19, associated with a development of glomerular fibrin thrombi caused by direct endothelial damage. ${ }^{29}$ In a recent observation, SARS-CoV-2 showed renal tropism, and RNA has been detected in the kidneys, with preferential targeting for glomerular cells. ${ }^{30}$ Furthermore, as observed in other virus-associated nephropathies, SARS-CoV-2 can directly infect human kidney tubules and also induce cytoplasmic renal tubular inclusions. ${ }^{31}$ The different sites of renal involvement are shown in Figure 2.

As mentioned, regardless of the direct viral kidney infection, SARS-CoV-2 determines an increase in the Ang II/Ang-(1-7) ratio. The result is AT1-receptor activation as well as a decrease in vasodilatation Ang (1-7) activity, with a subsequent risk of a worsening of the renal function. Thus, patients with chronic kidney disease (CKD), especially those with diabetic nephropathy, may have a higher risk of AKI because of an already existing upregulation of $\mathrm{ACE}$ and downregulation of 
Table I Studies Evaluating Prevalence of Kidney Injury During COVID-I9

\begin{tabular}{|c|c|c|c|c|c|c|c|c|}
\hline $\begin{array}{l}\text { Author } \\
\text { (Reference) }\end{array}$ & Country & $\begin{array}{l}\text { Type of } \\
\text { Study }\end{array}$ & $\begin{array}{l}\text { N CovID } \\
\text { Patients }\end{array}$ & $\begin{array}{l}\mathbf{N}(\%) \text { of } \\
\text { Males }\end{array}$ & $\begin{array}{l}\text { N (\%) of } \\
\text { Patients with } \\
\text { Severe Forms } \\
\text { Admitted to } \\
\text { ICU }\end{array}$ & $\begin{array}{l}\text { Median Age } \\
\text { (Range) }\end{array}$ & Definition of Kidney Injury & $\begin{array}{l}\text { N (\%) } \\
\text { COVID-19 } \\
\text { Patients } \\
\text { with Kidney } \\
\text { Injury }\end{array}$ \\
\hline $\begin{array}{l}\text { Arentz M, } \\
2020^{\circ}\end{array}$ & United States & Case series & 21 & Not reported & $21(100 \%)$ & $70(43-92)$ & $\begin{array}{l}\text { KDIGO definition* and the } \\
\text { International Society of } \\
\text { Nephrology }\end{array}$ & $4(19.1)$ \\
\hline $\begin{array}{l}\text { Chan L, } \\
2020^{10}\end{array}$ & United States & $\begin{array}{l}\text { Observational } \\
\text { study }\end{array}$ & 3235 & $1868(57 \%)$ & 815 (25.2\%) & $66.5(55.6-77.8)$ & $\begin{array}{l}\text { Increase in the peak serum } \\
\text { creatinine of at least } 0.3 \mathrm{mg} / \mathrm{dL} \\
\text { or } 50 \% \text { above baseline }\end{array}$ & $1406(46 \%)$ \\
\hline $\begin{array}{l}\text { Chen N, } \\
2020^{11}\end{array}$ & China & $\begin{array}{l}\text { Retrospective } \\
\text { single-center } \\
\text { study }\end{array}$ & 99 & $67(68 \%)$ & Not reported & $55(2 \mid-82)$ & $\begin{array}{l}\text { Increase in serum creatinine or } \\
\text { BUN }\end{array}$ & $3(3 \%)$ \\
\hline $\begin{array}{l}\text { Chen T, } \\
2020^{12}\end{array}$ & China & Case series & 274 & $171(62 \%)$ & $50(18.5 \%)$ & $62(44-70)$ & KDIGO definition* & $29(11 \%)$ \\
\hline $\begin{array}{l}\text { Cheng Y, } \\
2020^{7}\end{array}$ & China & $\begin{array}{l}\text { Prospective } \\
\text { cohort study }\end{array}$ & 701 & 367 (52.4\%) & $73(10.4 \%)$ & $63(50-71)$ & KDIGO definition* & $36(5.1 \%)$ \\
\hline $\begin{array}{l}\text { Guan W, } \\
2020^{13}\end{array}$ & China & $\begin{array}{l}\text { Observational } \\
\text { study }\end{array}$ & 1099 & 637 (58\%) & $173(15 \%)$ & $47(35-58)$ & $\begin{array}{l}\text { KDIGO definition* or presumed } \\
\text { to have occurred within } 7 \text { days; } \\
\text { or urine volume of below } \\
0.5 \mathrm{~mL} / \mathrm{kg} / \mathrm{h} \text { for } 6 \text { consecutive } \\
\text { hours }\end{array}$ & $6(0.5 \%)$ \\
\hline $\begin{array}{l}\text { Hirsch J, } \\
2020^{14}\end{array}$ & United States & $\begin{array}{l}\text { Retrospective } \\
\text { observational } \\
\text { cohort study }\end{array}$ & 5449 & $3317(60.9)$ & 1395 (25.6\%) & $64.0(52-75)$ & KDIGO definition* & $1993(36.6 \%)$ \\
\hline $\begin{array}{l}\text { Wang } \mathrm{H} \text {, } \\
2020^{15}\end{array}$ & United States & $\begin{array}{l}\text { Retrospective } \\
\text { observational } \\
\text { study }\end{array}$ & 19,249 & Not reported & Not reported & Not reported & $\begin{array}{l}\text { Using definitions established by } \\
\text { the Acute Kidney Injury } \\
\text { Network (AKIN) }\end{array}$ & $4369(22.7 \%)$ \\
\hline Xu S, $2020^{16}$ & China & $\begin{array}{l}\text { Retrospective } \\
\text { study }\end{array}$ & 355 & Not reported & $60(16.9 \%)$ & Not reported & $\begin{array}{l}\text { Any of renal functional indices } \\
\text { beyond normal range }\end{array}$ & $56(15.8 \%)$ \\
\hline $\begin{array}{l}\text { Yan Q, } \\
2020^{17}\end{array}$ & China & $\begin{array}{l}\text { Retrospective, } \\
\text { observational } \\
\text { cohort study }\end{array}$ & 882 & $440(49.9 \%)$ & $105(11.9 \%)$ & $71(68-77)$ & KDIGO definition* & $115(13 \%)$ \\
\hline $\begin{array}{l}\text { Zhang G, } \\
2020^{18}\end{array}$ & China & Case series & 221 & $108(48.9 \%)$ & $55(24.8 \%)$ & $55(39-66.5)$ & Not reported & $10(4.5 \%)$ \\
\hline
\end{tabular}

Notes: *KDIGO (Kidney Disease: Improving Global Outcome) criteria: AKI is defined as an increase in the serum creatinine level up to I.5 times the baseline level, or increase at least $0.3 \mathrm{mg} / \mathrm{dL}$ within the past 48 hours.

ACE2. ${ }^{32}$ A recent analysis including more than 17 million patients in the UK suggested that patients with CKD are at higher risk of mortality than those with other known risk factors, including chronic heart and lung disease. ${ }^{33}$

\section{Indirect Mechanisms of Renal Damage}

The indirect renal damage may be due to different mechanisms, such as renal hypo-perfusion, humoral response to viruses, thrombotic micro-angiopathy and activation of the complement system.

\section{Role of Renal Hypo-Perfusion}

Systemic hypotension, as a result of severe dehydration, low cardiac output or vasodilatation, may depress renal blood flow, causing ischemia and cell death.

Moreover, cardiac involvement in systemic inflammatory syndromes or acute viral myocarditis may lead to cardiac damage and subsequent cardio-renal syndrome type $1 .^{34}$ Lastly, a positive fluid balance may increase alveolarcapillary leakage and worsen ARDS and renal vein congestion, causing renal compartment syndrome, with a worsening of the AKI. 


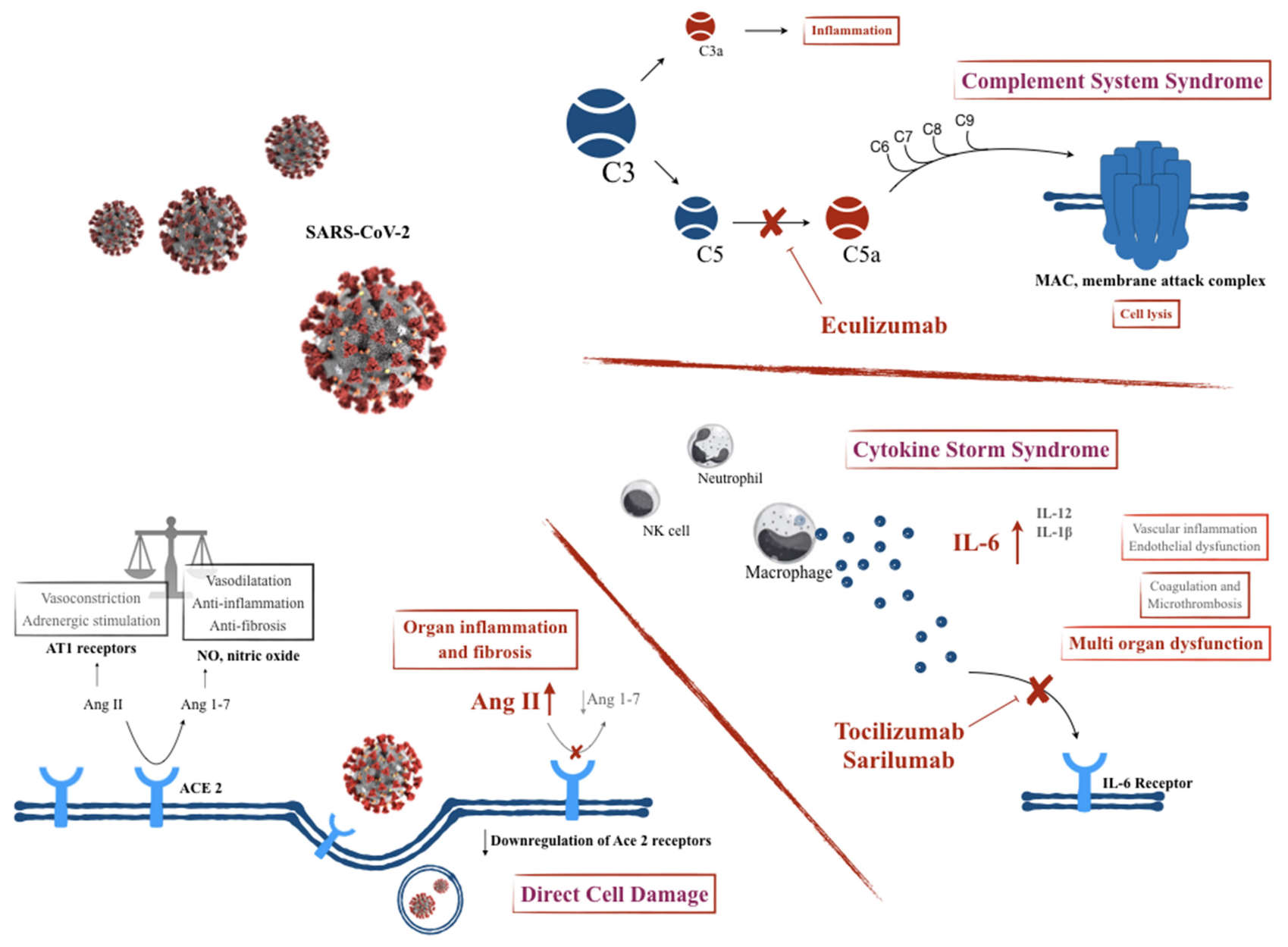

Figure I Pathogenesis of SARS-CoV2.

\section{Role of Inflammation and Thrombotic Microangiopathy}

Despite an extensive tissue distribution of SARS-CoV-2, several hypotheses on the mechanisms of organ involvement have been put forward, and most of them recognized a central role of the humoral immune system. COVID-19 determines the release of a huge number of proinflammatory cytokines. This condition is known as cytokine release syndrome (CRS) or cytokine storm syndrome (CSS). It is a form of systemic inflammatory response syndrome (SIRS) that accelerates cell death in several organs, and can ultimately lead to multiple organ dysfunction syndrome (MODS). ${ }^{35}$ It is also responsible for endothelial dysfunction and a pro-thrombotic action ${ }^{36}$ that can lead to small vessel vasculitis and extensive microthrombosis, a condition named thrombotic microangiopathy (TMA), one of the main causes of death in severe cases. $^{37,38}$ In patients with CRS, AKI might occur as a result of renal damage mediated by inflammation, endothelial dysfunction and microthrombosis, or indirectly, as mentioned.

Pro-inflammatory Interleukin-6 (IL-6) has a central role in CRS. Among patients with COVID-19, IL-6 plasma levels are increased in those with ARDS and a consequent worse prognosis. ${ }^{39}$ Injured renal tubular cells promote upregulation of IL- 6 that determines alveolar damage. In contrast, ARDS may cause renal medullary hypoxia and tubular cell damage, ${ }^{40}$ demonstrating the close relationship between the lungs and kidneys. For these reasons, Tocilizumab, a humanized monoclonal antibody against Interleukin-6 receptor (IL-6R), has been used in some protocols as a treatment for patients with severe COVID-19. ${ }^{41}$ Sarilumab, a drug with the same mechanism of action, has been assessed in an open-label study in 56 patients with severe COVID-19 pneumonia with hyperinflammation, showing no significant difference in clinical improvement and mortality 


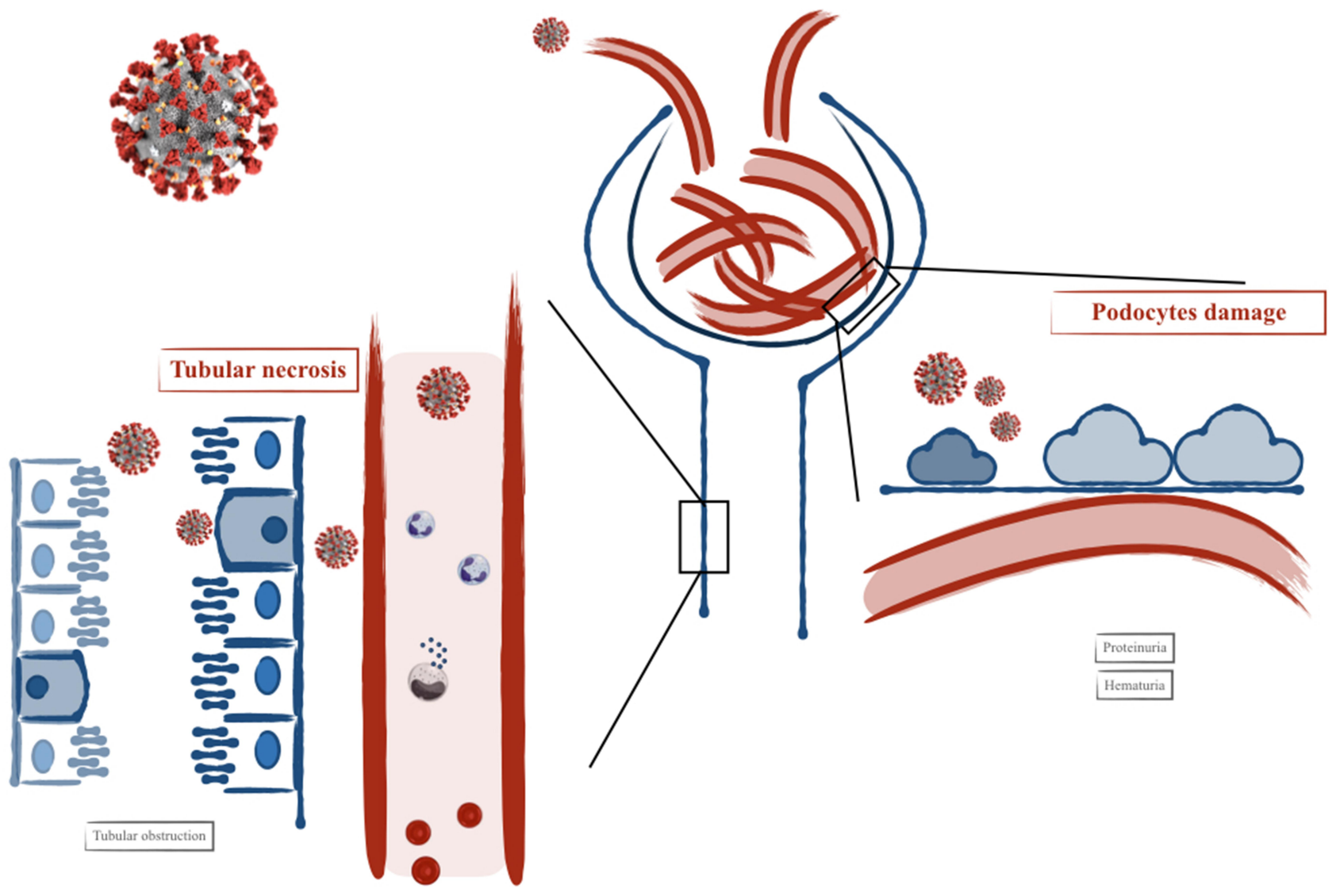

Figure 2 Sites of direct renal damage in SARS-CoV2.

at day 28 , compared with standard of care. ${ }^{42}$ On the other hand, in a case series of 8 patients, an improvement in respiratory symptoms and a faster discharge was observed in 7 treated with Sarilumab. ${ }^{43}$

Therapeutic plasma exchange (TPE or Plasmapheresis) could also be a strategy to remove pro-inflammatory cytokines, and it has been performed in an analysis on 31 patients admitted to intensive care unit (ICU) with ARDS or severe pneumonia. The TPE was associated with higher extubating rates and a lower mortality at day 14 and 28 post-plasma-exchange compared to controls. However, all-cause mortality was only marginally lower in the TPE group. Thus, randomized controlled clinical trials are warranted to draw conclusive findings. ${ }^{44}$

Interesting are the data on the patients who already were on immunosuppressive treatment, as those treated with calcineurin inhibitor (CNI)-based therapy after kidney transplant. Although kidney transplant recipients were expected to be at an increased risk of complications from COVID-19 owing not only to their chronic immunosuppression, but also to frequently associated comorbidities, in these patients the clinical presentation was generally mild and no patient progressed to ARDS. ${ }^{45}$ This evidence may be due to the fact that these patients were subjected to more stringent controls than the general population and that the long-term immunosuppressive regimen and the continuation of CNI treatment might have influenced the clinical course of the disease by preventing the occurrence of huge alveolar macrophage activation with consequent release of pro-inflammatory cytokines. ${ }^{46}$

\section{Role of the Complement System and Atypical Hemolytic Uremic Syndrome}

As a mediator of the innate immune response, the complement system may play a role in the pathogenic mechanism of organ damage in SARS-CoV-2 infection, as demonstrated in other acute respiratory syndrome coronavirus (SARS-CoV, MERS-CoV) infections. There are three biochemical pathways activating the complement system, all converging into a common pathway with the production of $\mathrm{C} 3 \mathrm{a}$ and $\mathrm{C} 5 \mathrm{a}$ (inflammatory mediators), C3b (for pathogen opsonisation) to the final formation of the C5b-9 membrane attack complex (MAC), that lyses targeted cells, resulting in cell death. 
In a murine model of SARS-CoV infection, lacking C3 and thus the impossibility to activate the complement pathway, decreased the severity of the disease with less respiratory dysfunction and lower cytokine levels, despite equal viral loads. The authors suggest that most SARSmediated diseases are likely immune-mediated. ${ }^{47}$ In a murine model of MERS-CoV infection, increased concentrations of C5a and C5b-9 were found in the sera and lung tissues. Blocking $\mathrm{C} 5 \mathrm{a}$ with a murine antibody alleviated lung and spleen damage, with decreased cytokine response and viral replication. ${ }^{48}$ In humans, excessive activation of the complement, similarly to CSS, leads to endothelial injury and the activation of the coagulation cascade, a condition named atypical hemolytic uremic syndrome (aHUS). aHUS is a form of TMA characterized by micro-angiopathic hemolytic anemia, thrombocytopenia and acute renal failure. Eculizumab is a recombinant humanized monoclonal antibody against $\mathrm{C} 5$ complement protein, used to modulate the activity of the distal complement pathway by preventing the development of the MAC, and approved to treat people with aHUS. In the SOLIDC19 study, Eculizumab has been used in the severe stage of COVID-19 patients to modulate the activity of the distal complement pathway, preventing the formation of the membrane attack complex. By modulating the distal complement cascade, organ damage can be halted while the patient has time to recover from the virus with symptomatic treatment, as described in the experience of a group from Naples, pending further confirmation from the ongoing SOLID-C19. ${ }^{49,50}$

Given the role of chemokine receptor type 5 (CCR5) in immune cell migration and inflammation, the impact of CCR5 blockade via the CCR5-specific antibody leronlimab (originally developed to treat HIV-1 infection) has been investigated for compassionate use in patients with critical COVID-19 disease. Despite the evidence of a reduction of plasma IL-6 levels and resolution of SARSCoV2 plasma viremia compared to controls, these results need for ongoing randomized clinical trials. ${ }^{51,52}$

\section{Management of Kidney Injury During SARS-CoV-2 Infection}

As yet, no drug or vaccine has been approved to treat human coronaviruses. In addition, no specific treatment options exist for kidney injury secondary to COVID-19, and the current care strategy is fundamentally supportive.
It is crucial to support the patient as early as possible, to increase the possibility of preventing the development of AKI and ensure a faster recovery. Patients with AKI (or at risk of $\mathrm{AKI}$ ) require attention to their hemodynamic status, with close control of blood pressure and cardiac output, to avoid renal hypo-perfusion and preserve glomerular flow. In critically ill patients, AKI may be caused or worsened by potentially nephrotoxic drugs or invasive mechanical ventilation, which requires attention to avoid ventilation-induced hemodynamic effects and barotrauma, especially in patients with ARDS or respiratory failure. ${ }^{23}$

\section{Pathogenetic Treatment}

The identification of an effective treatment against COVID-19 will indirectly allow avoiding or improving kidney injury during SARS-CoV-2 infection. Different treatment modalities and off-label medications are being evaluated or developed for the management of COVID-19. However, among all, only a few drugs have demonstrated the expected clinical or prognostic benefits.

Chloroquine/hydroxychloroquine inhibits viral entry and endocytosis of SARS-CoV-2 in vitro with beneficial immunomodulatory effects by reducing the release of proinflammatory cytokines. Despite this evidence, no clinical or prognostic benefits have been demonstrated. ${ }^{53-55}$

No benefits have been demonstrated by the use of the protease inhibitor lopinavir-ritonavir when compared with standard care, despite the positive effect in blocking viral replication in vitro. ${ }^{56}$

Some evidence about the antiviral remdesivir has shown to reduce both time-to-symptom resolution and duration of mechanical ventilation, but the effect on survival has not yet been proven. ${ }^{57,58}$

Target immunomodulatory therapies, like monoclonal antibodies (tocilizumab, sarilumab, evolocumab), are alternative therapeutic strategies used to contrast the immunity and inflammatory response in CRS, as mentioned above.

Anticoagulant therapy and thrombi prevention with low molecular weight heparin (LMWH) is recommended, because of the pro-coagulative state caused by virusinduced endothelial dysfunction, cytokine storm and complement cascade hyperactivation. ${ }^{5}$

Corticosteroids, ie dexamethasone, have shown a reduction in 28-days mortality in some patients in advanced stages in the preliminary results of the RECOVERY trial. ${ }^{59}$

The role of convalescent plasma has been investigated in the PLACID trial ${ }^{60,61}$ in patients admitted to hospital 
with moderate COVID-19: although a statistically significant higher rate of conversion to a negative result for SARS-CoV-2 RNA occurred on day 7 among patients in the intervention arm, no clinical benefit was associated with the use of convalescent plasma.

\section{Renal Replacement Therapy (RRT) and Blood Purification}

The optimal timing for dialysis in AKI is not clear and, generally, it must be avoided as long as possible. The decision to start RRT is mostly based on volume overload, hyperazotemia, hyperkalemia and severe acidosis. In patients with COVID-19 and AKI, early RRT seems to provide adequate organ support and prevent the worsening of the disease severity.

Continuous RRT (CRRT) by hemofiltration and hemodiafiltration is preferred in hemodynamically unstable patients because it contributes more to the resolution of the organ failure. Filter clotting is a major complication in these patients because of SIRS and the thrombophilic status. Therefore, focused anticoagulant therapy is mandatory, as also seen in other COVID-19 patients without AKI.

Continuous venovenous hemodialysis (CVVHD) may be an alternative solution. For patients with severe COVID-19 with sepsis and ARDS, blood perfusion/ plasma absorption treatment can also be useful to remove and replace inflammatory mediators. ${ }^{62}$

\section{Conclusions}

COVID-19 is a viral infectious disease mainly presenting with fever and pneumonia. Several data suggest an important role played by the immune system in critically ill patients leading to ARDS, multiple organ failure, and even death. Consequently, different pathways, in addition to viral damage, may contribute to organ damage. Kidney injury may occur and impact the prognosis. Antiinflammatory and supportive therapies are the cornerstones of treatment for severe cases, while in selected patients renal replacement therapy and extracorporeal blood purification may be applied.

\section{Acknowledgment}

Vanvitelli COVID-19 group: Nicola Coppola, Caterina Sagnelli, Stefania De Pascalis, Maria Stanzione, Gianfranca Stornaiuolo, Angela Cascone, Salvatore Martini, Margherita Macera, Caterina Monari, Federica
Calò, Andrea Bianco, Antonio Russo, Valeria Gentile, Clarissa Camaioni, Giulia De Angelis, Giulia Marino, Roberta Astorri, Carmine Minichini, Mario Starace, Alessandra Di Fraia, Ilario De Sio, Marco Niosi, Serena Borrelli, Benito Celia, Maria Ceparano, Salvatore Cirillo, Maria De Luca, Grazia Mazzeo, Giorgio Paoli, Vincenzo Carfora, Marco Di Mauro, Marco Giuseppe Migliaccio, Filiberto Fausto Mottola, Riccardo Ricciolino, Giorgio Spiniello, Nicoletta Verde.

\section{Disclosure}

The authors report no conflicts of interest for this work.

\section{References}

1. World Health Organisation. Novel coronavirus - China; 2020. Available from: https://coronavirus.jhu.edu/map.html.

2. Russo A, Minichini C, Starace M, et al. Current status of laboratory diagnosis for covid-19: a narrative review. Infect Drug Resist. 2020; Volume 13:2657-2665. doi:10.2147/IDR.S264020

3. Zhou F, Yu T, Du R, et al. Clinical course and risk factors for mortality of adult inpatients with COVID-19 in Wuhan, China: a retrospective cohort study. Lancet. 2020;395(10229):1054-1062. doi:10.1016/S0140-6736(20)30566-3

4. Macera M, De Angelis G, Sagnelli C, Coppola N. Clinical presentation of covid-19: case series and review of the literature. Int J Environ Res Public Health. 2020;17(14):5062. doi:10.3390/ijerph17145062

5. Carfora V, Spiniello G, Ricciolino R, et al. Anticoagulant treatment in COVID-19: a narrative review. J Thromb Thrombolysis. 2020. doi:10.1007/s11239-020-02242-0

6. Mottola FF, Verde N, Ricciolino R, et al. Cardiovascular system in COVID-19: simply a viewer or a leading actor? Life (Basel, Switzerland). 2020;10(9):165.

7. Cheng Y, Luo R, Wang K, et al. Kidney disease is associated with in-hospital death of patients with COVID-19. Kidney Int. 2020;97 (5):829-838. doi:10.1016/j.kint.2020.03.005

8. Ali H, Daoud A, Mohamed MM, et al. Survival rate in acute kidney injury superimposed COVID-19 patients: a systematic review and meta-analysis. Ren Fail. 2020;42(1):393-397. doi:10.1080/ 0886022X.2020.1756323.

9. Arentz M, Yim E, Klaff L, et al. Characteristics and outcomes of 21 critically ill patients with COVID-19 in Washington State. JAMA. 2020;323(16):1612. doi:10.1001/jama.2020.4326

10. Chan L, Chaudhary K, Saha A, et al. Acute kidney injury in hospitalized patients with COVID-19. medRxiv [Preprint]. 2020;32 (1):151-160. doi:10.1101/2020.05.04.20090944.

11. Chen N, Zhou M, Dong X, et al. Epidemiological and clinical characteristics of 99 cases of 2019 novel coronavirus pneumonia in Wuhan, China: a descriptive study. Lancet. 2020;395 (10223):507-513. doi:10.1016/S0140-6736(20)30211-7

12. Chen T, Wu D, Chen H, et al. Clinical characteristics of 113 deceased patients with coronavirus disease 2019: retrospective study. BMJ. 2020;368:m1091. doi:10.1136/bmj.m1091

13. Guan WJ, Ni ZY, Hu Y, et al. Clinical characteristics of coronavirus disease 2019 in China. $N$ Engl J Med. 2020;382(18):1708-1720. doi:10.1056/NEJMoa2002032

14. Hirsch JS, Ng JH, Ross DW, et al., Northwell COVID-19 Research Consortium; Northwell Nephrology COVID-19 Research Consortium. Acute kidney injury in patients hospitalized with COVID-19. Kidney Int. 2020;98(1):209-218. doi:10.1016/j. kint.2020.05.006. 
15. Wang HE, Muntner P, Chertow GM, Warnock DG. Acute kidney injury and mortality in hospitalized patients. Am J Nephrol. 2012;35 (4):349-355. doi:10.1159/000337487.

16. Shen X, Fu L, Fei J, et al. Acute kidney injury at early stage as a negative prognostic indicator of patients with COVID-19: a hospital-based retrospective analysis. medRxiv. 2020. doi:10.1101/ 2020.03.24.20042408

17. Yan Q, Zuo P, Cheng L, et al. Acute kidney injury is associated with in-hospital mortality in older patients with COVID-19. J Gerontol a Biol Sci Med Sci. 2020;glaa181. doi:10.1093/gerona/glaa181.

18. Zhang G, Hu C, Luo L, et al. Clinical features and short-term outcomes of 221 patients with COVID-19 in Wuhan, China. J Clin Virol. 2020;127:104364. doi:10.1016/j.jcv.2020.104364

19. Yang L, Xing G, Wang L, et al. Acute kidney injury in China: a cross-sectional survey. Lancet. 2015;386(10002):1465-1471. doi:10.1016/S0140-6736(15)00344-X

20. Khwaja A. KDIGO clinical practice guidelines for acute kidney injury. Nephron Clin Pract. 2012;120(4):c179-84. doi:10.1159/ 000339789

21. Robbins-Juarez SY, Qian L, King KL, et al. Outcomes for patients with COVID-19 and acute kidney injury: a systematic review and meta-analysis. Kidney Int Rep. 2020;5(8):1149-1160. doi:10.1016/j. ekir.2020.06.013

22. Pei G, Zhang Z, Peng J, et al. Renal involvement and early prognosis in patients with COVID-19 pneumonia. J Am Soc Nephrol. 2020;31 (6):1157-1165

23. Joannidis M, Forni LG, Klein SJ, et al. Lung-kidney interactions in critically ill patients: consensus report of the Acute Disease Quality Initiative (ADQI) 21 workgroup. Intensive Care Med. 2020;46 (4):654-672. doi:10.1007/s00134-019-05869-7

24. Serfozo P, Wysocki J, Gulua G, et al. Ang II (Angiotensin II) conversion to Angiotensin-(1-7) in the circulation is POP (Prolyloligopeptidase)-dependent and ACE2 (AngiotensinConverting Enzyme 2)-independent. Hypertension. 2020;75 (1):173-182. doi:10.1161/HYPERTENSIONAHA.119.14071

25. Ye M, Wysocki J, William J, et al. Glomerular localization and expression of angiotensin-converting enzyme 2 and angiotensin-converting enzyme: implications for albuminuria in diabetes. J Am Soc Nephrol. 2006;17(11):3067-3075. doi:10.1681/ ASN.2006050423

26. Ferrario CM, Jessup J, Chappell MC, et al. Effect of angiotensin-converting enzyme inhibition and angiotensin II receptor blockers on cardiac angiotensin-converting enzyme 2. Circulation. 2005;111(20):2605-2610. doi:10.1161/CIRCULATIONAHA.104.510 461

27. South AM, Diz DI, Chappell MC. COVID-19, ACE2, and the cardiovascular consequences. Am J Physiol Heart Circ Physiol. 2020;318 (5):H1084-H1090. doi:10.1152/ajpheart.00217.2020

28. Chappell MC, Marshall AC, Alzayadneh EM, Shaltout HA, Diz DI. Update on the angiotensin converting enzyme 2-angiotensin (1-7)Mas receptor axis: fetal programing, sex differences, and intracellular pathways. Front Endocrinol (Lausanne). 2014;5:1-13. doi:10.3389/ fendo.2014.00001

29. Su H, Yang M, Wan C, et al. Renal histopathological analysis of 26 postmortem findings of patients with COVID-19 in China. Kidney Int. 2020;98(1):219-227. doi:10.1016/j.kint.2020.04.003

30. Puelles VG, Lütgehetmann M, Lindenmeyer MT, et al. Multiorgan and renal tropism of SARS-CoV-2. $N$ Engl J Med. 2020;383 (6):590-592. doi:10.1056/NEJMc2011400

31. Batlle D, Soler MJ, Sparks MA, et al. Acute kidney injury in COVID-19: emerging evidence of a distinct pathophysiology. $J \mathrm{Am}$ Soc Nephrol. 2020;31(7):1380-1383. doi:10.1681/ASN.2020040419

32. Mizuiri S, Hemmi H, Arita M, et al. Expression of ACE and ACE2 in individuals with diabetic kidney disease and healthy controls. $\mathrm{Am}$ J Kidney Dis. 2008;51(4):613-623. doi:10.1053/j.ajkd.2007.11.022
33. Gansevoort RT, Hilbrands LB. CKD is a key risk factor for COVID-19 mortality. Nat Rev Nephrol. 2020;16(12):705-706. doi:10.1038/s41581-020-00349-4.

34. Ronco C, Reis T. Kidney involvement in COVID-19 and rationale for extracorporeal therapies. Nat Rev Nephrol. 2020;16(1):1-3. doi:10.1038/s41581-019-0226-4

35. Chousterman BG, Swirski FK, Weber GF. Cytokine storm and sepsis disease pathogenesis. Semin Immunopathol. 2017;39(5):517-528. doi:10.1007/s00281-017-0639-8

36. Libby P, Simon DI. Inflammation and thrombosis: the clot thickens. Circulation. 2001;103(13):1718-1720. doi:10.1161/01. CIR.103.13.1718

37. Tian S, Hu W, Niu L, et al. Pulmonary pathology of early-phase 2019 novel coronavirus (COVID-19) pneumonia in two patients with lung cancer. $J$ Thorac Oncol. 2020;15(5):700-704. doi:10.1016/j. jtho.2020.02.010

38. Huang X. Chinese society of neurology, Peripheral neuropathy collaboration group of Chinese Society of Neurology, Chinese society of electromyography \& Chinese society of neuromuscular disease. Chinese expert consensus on diagnosis and treatment of subacute combined degeneration. Chinese J Neurol. 2020;53:269-273.

39. Wu C, Chen X, Cai Y, et al. Risk factors associated with acute respiratory distress syndrome and death in patients with coronavirus disease 2019 pneumonia in Wuhan, China. JAMA Intern Med. 2020;180(7):934. doi:10.1001/jamainternmed.2020.0994

40. Husain-Syed F, Slutsky AS, Ronco C. Lung-kidney cross-talk in the critically ill patient. Am J Respir Crit Care Med. 2016;194 (4):402-414. doi:10.1164/rccm.201602-0420CP

41. Zhang C, Wu Z, Li JW, Zhao H, Wang GQ. The cytokine release syndrome (CRS) of severe COVID-19 and interleukin-6 receptor (IL-6R) antagonist Tocilizumab may be the key to reduce the mortality. Int J Antimicrob Agents. 2020;55(5):105954. doi:10.1016/ j.ijantimicag.2020.105954

42. Della-Torre E, Campochiaro C, Cavalli G, et al., SARI-RAF Study Group; SARI-RAF Study Group members. Interleukin-6 blockade with sarilumab in severe COVID-19 pneumonia with systemic hyperinflammation: an open-label cohort study. Ann Rheum Dis. 2020;79 (10):1277-1285. doi:10.1136/annrheumdis-2020-218122.

43. Benucci M, Giannasi G, Cecchini P, et al. COVID-19 pneumonia treated with Sarilumab: a clinical series of eight patients. J Med Virol. 2020;92(11):2368-2370. doi:10.1002/jmv.26062

44. Khamis F, Al-Zakwani I, Hashmi SA, et al. Therapeutic plasma exchange in adults with severe COVID-19 infection. Int $J$ Infect Dis. 2020;99:214-218. doi:10.1016/j.ijid.2020.06.064.

45. Azzi Y, Parides M, Alani O, et al. COVID-19 infection in kidney transplant recipients at the epicenter of pandemics [published online ahead of print, 2020 Oct 16]. Kidney Int. 2020;98(6):1559-1567. doi:10.1016/j.kint.2020.10.004

46. Cavagna L, Seminari E, Zanframundo G, et al. Calcineurin inhibitor-based immunosuppression and COVID-19: results from a multidisciplinary cohort of patients in Northern Italy. Microorganisms. 2020;8(7):977. doi:10.3390/microorganisms 8070977.

47. Gralinski LE, Sheahan TP, Morrison TE, et al. Complement activation contributes to severe acute respiratory syndrome coronavirus pathogenesis. MBio. 2018;9(5). doi:10.1128/mBio.01753-18

48. Jiang Y, Zhao G, Song N, et al. Blockade of the C5a-C5aR axis alleviates lung damage in hDPP4-transgenic mice infected with MERS-CoV. Emerg Microbes Infect. 2018;7(1):1-12. doi:10.1038/ s41426-018-0063-8

49. Diurno F, Numis FG, Porta G, et al. Eculizumab treatment in patients with COVID-19: preliminary results from real life ASL Napoli 2 Nord experience. Eur Rev Med Pharmacol Sci. 2020;24 (7):4040-4047. doi:10.26355/eurrev_202004_20875

50. Pitts TC.Eculizumab (Soliris) in covid-19 infected patients. Case Med Res. 2020. doi:10.31525/ct1-nct04288713 
51. Yang B, Fulcher JA, Ahn J, et al. Clinical Characteristics and Outcomes of COVID-19 Patients Receiving Compassionate Use Leronlimab. Clin Infect Dis. 2020. doi:10.1093/cid/ciaa1583.

52. Patterson BK, Seethamraju H, Dhody K, et al. CCR5 Inhibition in Critical COVID-19 patients decreases inflammatory cytokines, increases CD8 T-cells, and decreases SARS-CoV2 RNA in plasma by day 14. Int $J$ Infect Dis. 2021;103:25-32. doi:10.1016/j. ijid.2020.10.101.

53. Tang W, Cao Z, Han M, et al. Hydroxychloroquine in patients with mainly mild to moderate coronavirus disease 2019: open label, randomised controlled trial. $B M J .2020 ; \mathrm{m} 1849$. doi:10.1136/bmj. $\mathrm{m} 1849$.

54. Rosenberg ES, Dufort EM, Udo T, et al. Association of treatment with hydroxychloroquine or azithromycin with in-hospital mortality in patients with COVID-19 in New York State. JAMA. 2020;323 (24):2493. doi:10.1001/jama.2020.8630

55. Geleris J, Sun Y, Platt J, et al. Observational study of hydroxychloroquine in hospitalized patients with COVID-19. $N$ Engl $\mathrm{J}$ Med. 2020;382(25):2411-2418. doi:10.1056/NEJMoa2012410

56. Cao B, Wang Y, Wen D, et al. A trial of lopinavir-ritonavir in adults hospitalized with severe covid-19. $N$ Engl J Med. 2020;382 (19):1787-1799. doi:10.1056/NEJMoa2001282
57. Monari C, Gentile V, Camaioni C, Marino G, Coppola N, Vanvitelli Covid-Group. A focus on the nowadays potential antiviral strategies in early phase of coronavirus disease 2019 (Covid-19): a narrative review. Life (Basel). 2020;10(8):E146. doi:10.3390/life10080146

58. McCreary EK, Angus DC. Efficacy of remdesivir in COVID-19. JAMA. 2020;324(11):1041. doi:10.1001/jama.2020.16337

59. Horby P, Lim WS, Dodd LE, et al. RECOVERY Collaborative Group. Dexamethasone in hospitalized patients with Covid-19 - preliminary report [published online ahead of print, 2020. N Engl J Med. 2020. doi:10.1056/NEJMoa2021436

60. Agarwal A, Mukherjee A, Kumar G, Chatterjee P, Bhatnagar T, Malhotra P, PLACID Trial Collaborators. Convalescent plasma in the management of moderate covid-19 in adults in India: open label Phase II multicentre randomised controlled trial (PLACID Trial). BMJ. 2020;371. doi:10.1136/bmj.m3939.

61. Pathak EB. Convalescent plasma is ineffective for covid-19. BMJ. 2020;371. doi:10.1136/bmj.m4072

62. Ronco C, Bagshaw SM, Bellomo R, et al. Extracorporeal blood purification and organ support in the critically ill patient during covid-19 pandemic: expert review and recommendation. Blood Purif. 2020;50(1):17-27. doi:10.1159/000508125
Infection and Drug Resistance

\section{Publish your work in this journal}

Infection and Drug Resistance is an international, peer-reviewed openaccess journal that focuses on the optimal treatment of infection (bacterial, fungal and viral) and the development and institution of preventive strategies to minimize the development and spread of resistance. The journal is specifically concerned with the epidemiology of
Dovepress

antibiotic resistance and the mechanisms of resistance development and diffusion in both hospitals and the community. The manuscript management system is completely online and includes a very quick and fair peerreview system, which is all easy to use. Visit http://www.dovepress.com/ testimonials.php to read real quotes from published authors. 